WITTGENSTEIN ON FIELD AND STREAM

Stephen H. Daniel

The phenomenological description of the constitution of meaningfulness and evidence often is presented $(e . g$.$) by the lusserl of the Cartesian$ Meditations and the Crisis) in terms of a metaphorical vocabulary of "fields," "horizons," "streams," "flows," etc. Though other phenomenological themes have been recognized in some of wittgenstein's writings, his use of these field and stream metaphors in describing his family resemblances or private language positions has generally received very little attention. Perhaps the reason for this stems from a healthy caution about reading too much into a possible Husser1-wittgenstein connection. Such an attitude, however, is overly cautious in the case of the relationship of Wittgenstein to the psychological wri.tings of William James.

In Wittgenstein's Philosophical Investigations (PI) and zettel (z), there are repeated references to william James principles of Psychology (PP) and numerous passages which seem to parallel James ' treatments of a number of topics. One of the metaphors which appears in James' and Wittgenstein's treatments of the meaningfulness of the ideas we have and the words we use to express them is the contrast of considering ideas either in terms of a "stream" of thought or in terms of a state or "field" of static relations. James' prime concern is to show that the ideas we have have significance and value primarily in terms of the stream of thought in which they appear. For example, in the Principles, James writes:

Every definite image in the mina is steeped and dyed in the free water that flows around it. with it goes the sense of its relations, near and remote, the dying echo of whence it came to us, the dawning sense of whither it is to lead. The significance, the value, of the image is all in this halo or penumbra that surrounds and escorts it, - or rather that is fused into one with it and has become bone of its bone and flesh of its flesh; leaving it, it is true, an image of the same thing it was before, but 
making it an image of that thing newly taken and freshiy understood. (PP, I, P. 255)

Wittgenstein is more concerned with the meaning words have for us, but he does feel that James' point goes to the very heart of the discussion concerning the fact that words have meaning in terms of their use within the stream of thought, life, and experience.

This article is not a comparison of James and Wittgenstein on the stream of thought theme; nor is it meant to be a Jamesian interpretation of Wittgenstein on this theme. It is an examination of wittgenstein's treatments of meaning, intention, and understanding (and the rules involved with the understanding and use of words) in terms of Wittgenstein's use of the stream and field metaphors. The results of such an examination shed light on how a number of passages in the $\mathrm{PI}$ and $\mathrm{z}$ can be interpreted in terms of more familiar Wittgensteinian themes (e.g.) the family resemblances and private language discussions). 1

\section{Pictures in the stream}

Throughout the $\mathrm{PI}$ and $\mathrm{Z}$, Wittgenstein indicates that a proper description of the "meaning" of words should consist of (1) a recognition that the meaning of a word is grounded in the stream of experience, and that "only in the stream [Fluss] of thought and life do words have meaning" (2 173); and (2) a recognition that the elements of the stream can be singled out or temporarily considered apart from the stream in order to understand further the content of experience. Admittedly, the abstraction necessary for this second characterization of the meaning of a word does remove the word from its life-giving surroundings; but for the purpose of trying to understand what the word means, we must, as it were, step outside of the stream in order to see how we are using and interpreting the word in the stream:

If I see the thought symbol 'from outside', I become conscious that it could be interpreted this way and that way: if it is a step in the course of my thoughts, then it is a stoppingplace that is natural to me, and its further interpretability does not occupy (or trouble) me. ( 235)

In other words, seen "from the outside," a word is seen as the possibility of numerous meanings. The "course" or stream of thought, in the case of the second recognition mentioned above, is seen in terms of the steps and stopping-places which are seen as forming the content of experience. The meaning of a word is seen as 
frozen in a particular place in the stream, defined by its relationships with other elements of the stream. The further interpretability of the word does not occupy us because the interpretation has fixed the content of the word, i.e., within the frozen stream.

Indeed, the stream (once frozen) loses its character as stream and takes on the character of a state whose elements are actually fixed in their relationships to one another. In this way, the stream, as stream, can be understood as a field of possible applications or relationships (z 33.) The shift away from the on-going stream metaphor to the static field metaphor, however, is possible only when we continue to keep in mind the fact that, just as the meaning of a word is fringed in the stream by numerous relationships to other parts of the stream--relationships which become less and less clearly defined the farther forward and backward we look in the stream--so does this fringed character have to be maintained in our" discussions of the meaning of a word considered as static (i.e.. as a field or as a "picture").2 In other words, when we investigate the contents of ex-

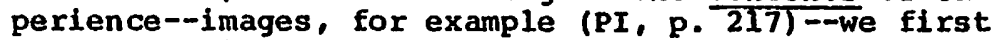
must recognize their "lifeless and isolated" appearance when considered outside of the stream ( $z 233$ ). and we must assume that any selection we make out of the stream--at least in order to approximate its appearance in the stream--is fringed with the possibility of forming other connections of words and
thoughts.

The elements of the stream, therefore, are fringed, just as the fields or the pictures (the stopping places) have fringes. Wittgenstein's discussion of these fringes is expressed in a number of metaphors: there are "shadows" of intention, concepts with "blurred edges," thoughts surrounded by "halos," "echoes," "an atmosphere," "an aura," "a corona," "half-shades." 4 The indefinite nature of the experience of the meaning of a word must be lifted out of the stream when we attempt to explain the difference between the meanings of various words. To Wittgenstein's question "Is there one difference of meaning that can be explained and another that does not come into daylight [zu Tage-note the contrast with "shadows" (Schatten) 1 in an explanation?" (z 156), we might answer (in a characteristically wittgensteinian way) : "Yes and No." Insofar as the picture-meaning of a word we have abstracted from the stream attempts to maintain the blurred edges which characterize "it" in the stream--and here I do not mean to imply that the stream blurs that which was previously clear--some difference of meaning between the word in other uses, 
or the word as compared to other words, could be explained and some difference of meaning could not. However, because of the blurred character of the picture-meaning of the word, apparently more than one difference of meaning could be explained, and more than one difference of meaning could not come out in any explanation.

\section{Intention, Meaning, and the Stream}

When we concentrate upon the stream character of the meaning of words and try to describe the meaning of a word according to the way we think it appears in the stream, we find that once we have selected a section of the stream or interpreted a section of the "space of intention" ( 233 ) in such a way as to yield a picture, the meaning of the word "is suddenly dead" (z 236): That is, once a picture of a word is fashioned within the stream, it can tell us little about the meaning of the word, if we assume that the meaning of the word is the intention an individual has in using the word or the interpretation he gives to a somehow already defined picture. But this is precisely the description which wittgensteln wants to do away with; to view intention and meaning as something which surrounds an object, a sign, a symbol--in brief, a picture--is to deny the importance of considering the question of meaning in the context of the stream: "If this intending, this meaning, is in turn something done with a picture, then I cannot see why that has to involve a human being" (z 236). Meaning is not something done with a picture, for this would imply that the picture Itself is fashioned apart from the influence of my intentions as interpreting the content of experience into pictures. The picture itself is an interpretation of the intention which characterizes a particular locus of the stream. However, because wittgenstein is interested in the further description of the meaning of a word, he feels justifled in

"taking a slice" (as it were) of the stream.

In making such a selection, in painting such a picture, we run the risk of thinking that the picture is the interpretation of the intention, and that this picture is the one meant when an individual intends a meaning for a word: this, again, assumes the priority of a picture whose elements are already given. Admittedly, Wittgenstein does allow for the fact that the content of experience does include "natural" stopping-places or "real things" which are the terminal points of relations realized in the stream: "when we intend, we are surrounded by our intention's pictures. and we are inside them. - . When we intend, we exist in the spaces of intention, among the pictures (shadows) 
of intention, as well as with real things" (z 233). In the stream we are surrounded on all sides by real things which become meaningful insofar as they are recognized (or "cognized") as being related to our perspective in the stream (i.e.. to our intention). The phrase "the intended meaning of a word" primarily refers to the fact that elements (the "real things") of the stream have been connected in the stream (and, therefore, actualize certain relationships and exclude the possibility of others). Elements in the stream, however, are not said to have an aura, a halo, or an atmosphere about them, because their very place in the stream (their surroundings and atmosphere) determine what the objects are: "Thus the atmosphere that is inseparable from its object--is not an atmosphere" (PI, P. 183). The object is a "real-thing"-in-relation, i.e... a thingin-the-stream.

But here is where we continually have to pull ourselves back into emphasizing the priority of the stream and the need to start with the intention, and then work back to the picturing, rather than vice versa. To make the picture prior is to admit of different interpretations for the picture--which is to imply that our stream of experience is really numerous streams. Wittgenstein, however, proposes that such a description of the stream of experience is incorrect. In itself, the picture is capable of numerous interpretations and of, therefore, numerous meanings; but no meaningful picture is seen "in itself"; it is always seen as an intended picture (2 233)--or more precisely, a picture within intention=-not a picture of the intention.

This point is of prime interest in interpreting the passage, which I have quoted above, in which wittgenstein gays that when we intend, we are surrounded by the pictures of our intention: and, that at any point in the stream, there is only one intention and only one meaning to a word or thought (however blurred that meaning is)--this, because the stream itself is singular. However, the elements of experience which are connected (and in a sense made what they are) through the intention, form the pictures [note the plural) of our intention. These pictures have life only in the flow of the stream or, as Wittgenstein calls it, in the space [Raum] of intention. 5 But because of the fleeting nature of intention, 6 i.e., because of the on-going movement of the stream, the relationships of "real things" are "pictured" in terms of the intention in a fleeting or shadowy manner. This is why wittgenstein refers parenthetically to the pictures of the intention as 
shadows: they are defined only to the extent that an individual is interested in defining them, i.e.. to the extent that the intention demands: "the intention seems to interpret, to give the final interpretation: which is not a further sign or picture, but something else--the thing that cannot be further interpreted. But what we have reached is a psychological, not a logical, terminus" (z 231). The final interpretation occurs in the course of the stream (the psychological terminus) and does not allow for further interpretation, because no further interpretation is made in the stream. ("What happens is not that this symbol cannot be further interpreted, but: I do no interpreting. I do not interpret, because I feel at home in the present picture" [z 234].) The relationships and connections in the stream are thematized according to the intention which is operative at that point in the stream: "Describing an intention means describing what went on from a particular point of view, with a particular purpose. I paint a particular portrait of what went on" $(z 23)$. But this does not imply that the characterization of the elements of experience and their relations are specifled in any way other than to the degree appropriate to the intention.

To compare concepts is to compare streams of thought (which, as we shall see below, is to compare ways of understanding). The ways that a word is used and the ways that concepts are formed depend upon the character of the stream. The narrower the stream and the more definite the concept, the more likely we are to think of the possibility that our pictures could symbolize the indefiniteness of our concept. 7

The character of the picture, however, is specified to the extent that the intention is specified, $i . e .$. to the extent that the stream is said to be this or that particular (personal) stream. The more varied the stream -we might say to continue the metaphor, the wider and slower moving the stream--the less likelihood that the poet's words, for example, can "pierce" us--" and that is of course causally connected with the use that those words have in our life. And it is also connected with the way in which, conformably to this use, we let our thoughts roam up and down in the familiar surroundings of the words" (z 155). Insofar as we allow our concepts indefiniteness, we allow their meanings to be more and more vague and open ourselves up to new and perhaps striking usages of these words.

Again, Wittgenstein's language abounds in metaphors of movements: different streams are those in which life "runs on" differently (z 388$)$, the concepts of others

"cut across" ours (2 379); the extent to which the 
poet's words pierce us is connected with the way we let our thoughts "roam up and down" in the familiar surroundings of the words ( $\underline{Z}$ 155). The emphasis on movement is an important counterbalance to wittgenstein's description of meaning in terms which often exphasize the static content of meaningful words.8

The on-going, flowing connotation of the meaning of words places special emphasis on the temporal dnscription of the stream. A word has meaning in the present not only because of the fact that it is an interpretation of the inter-related elements in the stream at the present point in the stream, but also because of the fact that these elements are related to elements beyond the vague limits of that section of the stream which we select out for close scrutiny. In other words, previous elements in the stream affect the way that present pictures are constructed and seen when we look into the meaning of a particular word we use. Likewise, future elements in the stream influence the make-up of the meaning of a word as it appears in the present section of the stream. The past and future are internally related to the present to the extent that any discussion of the meaning of words must provide for the fact that the intended picture (or "object") appears as it does because of the influence of the past on the present intention and the backward-reaching echoes of the future on the present intention:

What $I$ perceive in the dawning of an aspect is not a property of the object, but an internal relation between it and other objects. It is almost as if 'seeing the sign in this context' were an echo of a thought. 'The echo of a thought in sight'--one would like to say. (PI, p. 212)

What the metaphor of the stream indicates is that "intention" is the complexion (or form, arrangement) of the "real things" in the stream (i.e.. the contents of experience). These real things do not become meaningful until they are cognized as objects (i.e.. placed in relationships to other things) in the personal stream of experience. The "meaning" of a word refers to the combination of form and matter, of arrangement and components (with the understanding, though, that the components or objects themselves are what they are partially because of the intention).

Because of the temporal aspect of the stream, Wittgenstein finds that we are faced with a problem when we attempt to describe the experience of the meaning of a word. For when we use a word without, as it were, "watching ourselves" using the word, we have a different intention--and, therefore, are surrounded by different 
pictures--than if we were trying to describe the way we use a word, concentrating on "seeing" its meaning for us. The very concentrating on attempting to see the meaning--i.e., how we use the word--influences how we do, in fact, use the word. Thus, we fail to describe the "real" meaning which we intended for the word because the intentions in the stream have changed. In fact, when I attempt to explain the experience of meaning, I imply that I can step outside of the stream to take a look at what "I" experienced in some other (previous) part of the stream: as Wittgenstein asks, "But isn't it true, then, that the word means that to me now? Why not? - . ' When I uttered the word just now, it meant to me.' Why should that not be mere lunacy? Because $I_{-}$experienced that? That is not a reason" (z. 181-182) 79 "When I am conscious of my meaning a word. the consciousness of my intending that meaning itself contributes to the characterization of the meaning of the word: this is why the meaning is said to be different.

The important question which grows out of this particular discussion is: Can I ever know what I mean when I use a word, or can I ever know what I meant when I have used a word? According to the points we have just seen, it would appear that we would have to answer with an unqualified "No" to the first part of this question and with a qualified "No" to the second part -with the second "No" being contingent on the re not being an internal relationship between the present, past, and future "parts" of the strearn. That is, to some extent I can know what I meant when $I$ have used a word, because the meaning of the word $I$ have used "echoes" in my present use of the word, either (1) in virtue of the echoing effect set up by the bare similarity of the contents of the experience (e.g.., the visual or auditory images), or (2) in virtue of the echoing effect set up by the characterization of these elements (i.e.., the effect set up by the intention), or (3) in virtue of both content and intention echoes. (Some familiar expressions might illustrate the distinctions I am setting up here among these three echo conditions. For example, in regard to content echoes: "I don't remember using it, but if I used the word "gargoyle," I must have meant. . . ": in regard to intention echoes: "It really doesn't matter what $I$ said, just as long as you got my message"; and in regard to a combination of echoes: "I tried to express $i t$, as $I$ remember, as best
$I$ could. "10

The problematic way of speaking about meaning in terms of the stream strikes wittgenstein most when he begins to ask himself whether someone can use 
words meaningfully, even though that person is only vaguely aware of how he wants his words to be understood. For example, while thinking about two different friends, he sits down to write a letter; the question arises: "Can I be in doubt which of the two I was writing to?" $(z)$. The implied answer seems to be "Yes." and not onIy for the reason that later on he can decide on which one to send it to. The letter can still be meaningful even though it is not sent to either one, if the intention which was operative at the time of the writing simply demanded that the reader be someone like the two friends.

In short, there is no need to conclude that the meaning of a word becomes more specified the farther into the past and future we characterize or specify relationships. When I mean something, I need not imply-indeed, it is doubtful whether I can imply--that the ripples of future elements in the stream of experience indicate, any more than in a vague manner, what the character of those future elements are. With the exception of those experiences which are in the very near future and which we feel we have control over (such as willing to move our arm), most future elements are anticipated in a shadowy way, because they are (from the present perspective) overwhelmingly determined by their "future-ness." This is what wittgenstein is alluding to when he remarks that "the shadowy anticipation of a fact consists in this: we can now think that that thing will happen which only will happen" (2 62) "The dominant aspect of an anticipated fact is that it is anticipated; it is not first and foremost a determined fact which just so happens to be further along in the stream. It has an indeterminate and shadowy character because of what it is in the present. When (and if) that element of the stream becomes an object in a present field of experience, then it will have become, in fact, a different object: "if the indefiniteness were missing we should also not have 'the same thing meant" ( 2381$)$.

Wittgenstein wants to maintain that in some sense the future meaning of the word we use in the present is present when we use it--it "anticipates" reality. But the reality which is anticipated is shadowy because of its being in the future-in-terms-of-the-present. such a shadowy description of the future aspect of the meaning of the word is demanded by the fact we never "physically arrive," in the present, at the realization of the determinate future meanings of the word we presently use. This is the area for caution for Wittgenstein; we should not think 
that

when you meant it your mind as it were flew ahead and took all the steps before you physically arrived at this or that one. Thus you inclined to use such expressions as: The steps are really already taken, even before $I$ take them in writing or orally or in thought.' And it seemed as if they were in some unique way pre-determined, anticipated-as only the act of meaning can anticipate reality. (PI 188)

But even if, in meaning a word, we do not take all the steps--i.e.., we do not completely anticipate reality--in some "unique way" we still do anticipate reality, and future reality is in a sense predetermined because the present echoes in the future. But the puzzling and yet necessarily true description of the meaning of our words in the stream lies in the fact that the future is echoing in the present. To grasp the whole use of a word in a flash (in the present), then,

becomes queer when we are led to think that the future development must in some way already be present in the act of grasping the use and yet isn't present. For we say that there isn't any doubt that we understand the word, and on the other hand 1 ts meaning lies in its use. . . Don't I know, then, which game I want to play until I have played it? or are all the rules contained in my act of intending? . . . is it impossible for me to be certain what I am indending to do? (PI 197)

Wittgenstein's point here, just as in the letterwriting example, is that I might be uncertain as to what $I$ am in fact intending to do or to mean-but a higher degree of certainty might not be required by my present state of mind--i.e.. certainty to the extent that it is appropriate for me to be certain or to understand the word. The game that I know $I$ want to play in the future is in some sense a different game when I am playing it in the present: because, before I play the game, it is seen as a future part of the stream, but when $I$ play $i t$, it is characterized by the present intention of the stream.

III. The Field Aspects of Meaning

Even though the stream-like description of meaning holds a position of primacy in Wittgenstein's 
discussion, he does not want to ignore the more static aspects of the meanings of words. And in this regard, we have to consider the matter in two different, though related, ways.

First, when we attempt to talk about the meaning of the words we use in more than their stream-like character, we first "freeze" or "take a slice" of the stream-i.e., we see that part of the stream in terms of a picture. The important point to keep in mind in the selection of such a picture is that the edges of the picture are to be left sufficiently blurred so as to approximate the lively, moving character of the stream. The complexion of the picture, of course, will determine, to some extent, what those edges will look like; that is, the blurred edges of the picture are the edges of this picture. and, therefore, have characteristics which the edges of other pictures would not have.

This is an important point, not only to show how this first way of speaking about meaning "statically" differs from the second way (which we will describe below), but also to show that the complexion (or intention) of the stream at any point indicates the limits of the possible meanings that a word can have. In this way, the intention excludes other possible meanings that the word can have in the stream. The complexion of the stream indicates-albeit in a blurred way--that the stream can move in certain directions or "paths"-- land the plural is important herel-which are thus made real possibilities (instead of "pure" possibilities) and "famlliar" paths. When Wittgenstein writes that "the possibility of this movement must be the possibility of just this movement," what he is indicating is that, in the stream, future possibllities become limited without becoming actual: real possibility is, indeed, "something very near reality" (PI 194)--and here "reality" refers to that which is actual, i.e., that which is "realized" in the present part of the stream. The past and future are real insofar as they are "echoing" in the present, and the various past and future uses (meanings) of the words we presently use are "familiar" to the way we presently use the words, insofar as they are real possibilities. So when wittgenstein remarks that." a multitude of familiar paths lead off from these words in every direction" (PI 525 and 534), he is saying not only that certain remarks spur us to familiar insights, but also that those insights are in some sense anticipated because of their familial realtionship to what is focal for us at present.11 
To speak about this first way to describe the static aspect of meaning is to emphasize the picture metaphor $--i . e .$. the metaphor in which a picture is seen in terms of the stream, as having blurred edges or a "halo." But, as wittgenstein notes, someone would never have thought that a sentence or a thought had such a halo, atmosphere, or aura which might be separated from it if he had not thought "of how one might say it differently" (PI 607). That is, only when we consider the fact that the sentence or thought must primarily be understood in terms of that which gives it its life and meaning (viz.. the stream of thought or experience), can we appreciate the fact that familiar (somewhat determinate) paths lead off from our words "In every direction," i.e., indicating numerous real possibilities for the application or futher picturing of our words.

The second way to describe the static aspect of meaning is presupposed by the first: if the first way, as it were, "pictures" the real possibilities or paths which are cognized as "familiar" in terms of the present part of the stream, then such a description would assume an order of pure possibilities or paths (relationships) which are capable of perhaps becoming real possibilities in terms of some stream. When these pure possibilities become real possibilities in terms of this or that particular stream (i.e.., when they are cognized as the possibilities referred to in the blurred edges of pictures), they have the capacity of becoming realized, cognized objects in some part of the particular stream. Logic presents the description of this twice-removedfrom-the-stream order of pure possibility:

Thought is surrounded by a halo. - - Its essence, logic, presents an order, in fact the a priori order of the world: that is, the order of possibilities, which must be common to both world and thought. . . . It is prior to all experience, must run through all experience; no empirical cloudiness or uncertainty can be allowed to affect it. (PI 97)

In spite of the fact that this passage is an expression of a position which wittgenstein held in the rractatus and with which he is now uncomfortable, he is not rejecting the position that an a posteriori logic is possible. That is, the juxtaposition of the first sentence of this passage ("Thought is surrounded by a halo") with the denial of empirical cloudiness in logic (at the end of the passage) highlights Wittgenstein's later claim that meaningfulness in possibilities is determined according to the actualities which surround thoughts in the stream in a "halo-like" manner. 
The real world, however, is the cloudy and uncertain realm of the stream of experience; this perhaps becomes "clarified" when we abstract pictures (or halo-surrounded thoughts) from the stream; and when we go that one step further, not only removing the distinction' between actual relationships (or actualities) and real possibilities-not-yet-actualities, but also removing the distinction between real possibilities and pure possibilities, we see how the order described in logic is indeed far removed from, though in the "logical" order prior to, meaning and life.

The pure logical relatedness of elements is the bare minimum requirement for meaningfulness; that is, logical relatedness is in a minimal sense meaningful as an abstraction from (or an interpretation of) the more meaningful but more blurred level of pictures; these pictures are, in turn, meaningful as abstractions from (or interpretations of) the stream of thought and life. By themselves, the interpretations do not determine meaning (PI 198), although they do indicate how we can speak about meaning in terms of the various "levels of thought" implicit in the stream: "when I interpret, I step from one level to thought to another" (z 234). That is, the more I interpret the meaning of a word $I$ use, the more I make determinate that which in the stream had meaning and 11 fe because of its relative indeterminateness. The more I try to give the stream the character of a field, the more it will appear that an element, isolated from its place in both the stream and the picture, has meaning in itself:

If a sentence can strike me as like a painting in words, and the very individual word in the sentence as like a picture, then it is no such marvel that a word uttered in isolation and without purpose can seem to carry a particular meaning in itself. (PI, P. 215)

Again, Wittgenstein's warning is that in order for our words to have meaning, they must have meaning primarily in terms of the stream--i.e., the stream must be our starting point: to start at the level of logic is to admit that words do have meaning in themselves, i.e.. as distinct from their belng elements in the stream and components found in picture-objects.

When we intend, we are surrounded by the pictures of our intention: above, I emphasized what wittgenstein means by this in terms of the stream metaphor. But we can also interpret him in terms of the more static fleld image, if we recognize that just as a sentence or thought can be seen as a "field [Feld] of force" that 
is decisive in determining the meaning of a word (PI, p. 219), so also individual pictures ("themes," "objects") can be statically interpreted as meaningful in terms of the "whole field [Feld] of our languagegames" (z 175). However, when we begin to compare various ways in which we use words, what we do is compare various parts of the stream to one another. Or, to put it simply, we treat the stream as the "whole field of our language-games." This use of the word "field" would be misleading if we were to conclude from it that the stream is, in fact, a field. The major advance, in Wittgenstein's own eyes, of the Investigations over the Tractatus is precisely in his recognition that the description of meaning should proceed from the viewpoint of the stream to interpreting meaning as field--first in terms of pictures and, then, in terms of logic:--not (as in the Tractatus) from the starting point of a description of pictures and, then, to directing our explanation toward the logical substructure of those pictures.

IV. The Rules of Language-Games: "Understanding" in Stream and Field

Seen in terms of the stream of experience, the "rules" of the various language-games we play refer to the general reasons we give to justify our speaking of some objects in the stream--and, therefore, the paths or routes of relationships to those objects--as

"familiar." Objects (or "pictures") further along in the stream are familiar insofar as they refer to (1.e.. are in accord with or are not in accord with) the rules which describe how elements in the present part of the stream are related to one another as establishing the condition of meaningfulness. The rules of a game which an individual has not as yet played are less determinate (actual, real) than those which describe the game he presently plays--but this does not mean that he does not have, at least in some sense, a picture of a game in advance of his playing it. However, the picture he has of a future game describes a future configuration of the stream in terms of, and from the perspective of, the present game.

The meanings of the words we use, therefore, will be familiar insofar as those usages are allowed for in the rules or technique of the game we intend to play or assume ourselves to be playing.12 What our words mean in the future are already in some sense "pictured" in the present: we are playing games whose rules are often vague ( $\mathrm{PI} 100)$, perhaps even unknown to the person playing the game (PI 82,679$)$, and capable of having different roles in the game (i.e.. different applications and, therefore, indicating different meanings in 
the stream) (PI 53). We are entangled in our rules because we are caught up in the stream, and the rules we envision for the use of our words are determinate only to the extent that the future is determinate in the present.

The rules of a game tend both to indicate how the game should be played (i.e... how the game should progress) and to describe, within certain general limits, what we should see if we were to freeze the progress of the game at any point. Or in terms of our discussion here, rules are wittgenstein's way of speaking about the characteristics of the formal appearance (or intention) of the stream of thought and iife. That is, the rules according to which we determine the meanings of words we use are gleaned from our recognition of how, in fact, we use the words in the stream. In painting a picture of any point of the stream, we see a portrait with a certain formal structure (or set of rules) which attempts to explain the meaning of the word we use at the same time as indicating (through the very vagueness of the rules) that such a picture should not be interpreted apart from considering it as in the stream.

Rules are the formal links between pictures in the stream. Or to put this in another. way, if we were to see the stream as a series of continualiy overiaping pictures (or "objects of experience"), then the rules which we would imagine as indicating how the elements of those pictures have meaning could be "read of $f^{\prime \prime}$ of the pictures. Unfortunately. because the pictures are seen to overlap, $i . e .$, because of the primacy of the stream, the rules we read off of the pictures can only generally explain the meanings of the words we use. In order for us to describe fully what the understanding of the meaning of a word involves, we must try to read the rules off of the stream itself--that is, off of the way the words are used:-we must try to imagine the rules of the intention itself, instead of concentrating only on the pictures of the intention. Thus, the description of understanding must involve discussions both of the rules indicated in the "explanations" given by the more static picture or field images, as well as of the rules (i.e., the "training") which are (is) found in the movement of the stream: "Understanding is effected by explanation; but also by training" (2 186).

Understanding, according to wittgenstein, has characteristics of both the field and the stream, the state and the process. Understanding is both a state (PI, p. 59n) having characteristics of processes (PI 154), as well as a process or act having characteristics of a state (e.g., an "atmosphere") (PI $609 \&$ Z 217). 
Understanding is an interpreting of the elements of the stream in such a way as to see those elements now as one object (or picture) and now as another object (or picture).

Interpreting the content of the stream is not necessarily the same as making an interpretation of the stream: "You see it conformably, not to an interpretation, but to an act of interpreting" (z 217). To equate the two would be to lessen the influence the interpreting has on the very makeup of the content of the stream: the elements of the stream are what they are because they are in the stream. When the act of interpreting (i.e.., the intention) is "seen" as an interpretation, the seeing becomes a state-a "seeing according to an interpretation" ( $\underline{z}$ 212; PI, p. 200)--that is, it yields a picture.

I want to ask: what constitutes seeing the figure now like this, now another way?--Do I really see something different every time? or do $I$ merely interpret what $I$ see in a different way?-I am inclined to say the first. But why? Well, interpreting is a procedure.. Seeing is not an action but a state. (2 208) 13

The activity of thinking, the activity of interpreting--in short, the flow of thought and experience --indicates that the figure or object I "see" is different in different parts of the stream. I do not simply see different aspects of the same object--this position would assume that the object (or picture) in itself has the characteristics which the interpretation of elements in the stream characterizes as this picture (NOT "a picture of this"). I do not "see" a this whose "aspects" can be said to change according to my interpretation: "we see, not change of aspect, but change of interpretation" (2 216)--that is, the stream is said to "change," but not the objects (or plctures) in the stream: "I really see something different every time." It is only in terms of the stream that I can really speak about "this" picture, this experience; only when we go back and try to "see" what happened in the stream (i.e.. when we take a slice of or freeze the stream) are we able to get a "picture"--hopefully one with blurred edges--of the stream at that point: "It is only if someone can do, has learnt, is master of, such-and-such, that it makes sense to say he has had this experience. . - We talk, we utter words, and only later get a picture of their life" (PI, p. 209).

The picture metaphor is necessary to the description of understanding and meaning; otherwise, the 
objects of experience would all run together, becoming so blurred that we would not have any "stopping-places" around which to develop relatively stable meanings for the words we use. The flowing, doing, thinking ["to interpret is to think" (PI, p. 212)], interpreting characteristics of meaning are important; but if we fail to include the picture character of meaning, then our description of meaning will be incomplete: "for "to mean it' did not mean: to think of it" (PI 692).

When someone says the word 'cube' to me, for example, I know what it means. But can the whole use of the word come before my mind, when I understand it in this way? Well, but on the other hand isn't the meaning of the word also determined by this use? And can these ways of determining meaning conflict? . . What really comes before our mind when we understand a word? Isn't it something like a picture? Can't it be a picture? (I 692)

Indeed, when I understand a word, it is meaningful because it is something like a picture--but, it is this or that picture because it is seen in terms of this or that use. What is it that I know when I say I know what the word "cube" means?--Nothing more than the fact that I could form a picture (or pictures) of a cube depending upon what part of the stream of experience $I$ select-1.e.. depending upon what I an "thinking" about when I use the word "cube": "What I can see something as, is what it can be a picture of. . . What this means is: the aspects in a change of aspects are those ones which the figure might sometimes have permanently in a picture" (PI, p. 201). When we assume that the picture takes primacy over the stream, we are forced into making statements such as the one just quoted: we are forced to speak about a figure having aspects which are "sometimes permanent." This awkward juxtaposition of the temporary and the permanent should indicate to us that there is something strange (indeed something wrong) in assuming that the picture is the permanent thing here and that interpretations of its aspects are what characterize its being a part of the stream of experience.

This does not rule out, however, the possibility that certain pictures come to mind when $I$ use a word more readily than other pictures. Those pictures are more "familiar" to me whose elements or intentions (or whose combination of both elements and structures) are echoing in the present place in my stream of experience. When I see a shape, therefore, it is not just any shape --it is not a pure possibility: it is a shape which is 
familiar to me because of the fact that at some previous point in the stream it became a real possibility for experience, an object with a "familiar pattern":

This shape that I see--I want to say--is not simply a shape: it is one of the shapes I know: $i t$ is a shape marked out in advance. It is one of those shapes of which I already had a pattern in me; and only because it corresponds to such a pattern is it this familiar shape. (I as it were carry a catalogue of such shapes around with me, and the objects portrayed in it are the. familiar ones.) (2 209)

The patterns or paths which are familiar to me are familiar because of the continuity of relation in the stream of experience. The stream thus provides the unifying force necessary for considering objects as familiar: they are related to one another, and resemble one another, by virtue of their being objects of a personal stream of experience.

\section{Concluding Remarks}

It should be apparent by now that underlying wittgenstein's discussion of meaning as use is a recurring theme: words are meaningful because they are used in the context of personal experience. When they are taken out of this context they lose in liveliness and intensity while possibly gaining in immediate clarity. The important word here however is "possibly": the taking of a slice of the stream of experience is always according to an interpretation and, therefore, is always open to (and indeed fosters) incompletedness by setting out the whole matrix of interrelatedness which seems to be at the basis of all life and thought (viz. logic). But in the process, we are drawn further and further away from the actual and really meaningful stream of personal experience toward the cold and lifeless realm of pure possibility. Indeed, in the process of trying to clarify the meanings of the words we use, the appeal to the logical basis of interrelationships has resulted in providing a treatment which does away with the iliness of having unclear meanings for words, but at the expense of the life of the language. It is the drastic surgery entailed in a logical analysis of language which wittgenstein wants to call us away from; in fact, his purpose appears to be to re-orient the way we speak about language. Perhaps, in such a re-orientation, we might see something inherently destructive and alien to language in logical clarity and preciseness. We might also see that such logical clarity might constitute what 
is often referred to as "the present, on-going deterioration of language" instead of acting as a means of preventing such a deterioration.

Saint Louis University 


\section{NOTES}

${ }^{I}$ In general, I have focused my attention on the PI (Anscombe translation) and $\underline{z}$ (Anscombe translation), and in a number of places I have made some silent emendations of the English translations. The numbers which follow the title abbreviation refer to the sections of $z$ and the first part of the PI from which the quotations are taken; page numbers are given for quotations taken from the second part of PI and from the footnotes of the first part. Ali underlining is that of wittgenstein.

${ }^{2}$ Here, two uses of the word "picture" [Bild] should be distinguished: first, it functions as a term within a theory of language (especially that found in the Tractatus): and secondly, it functions as a methodological or meta-level term in association with the "field" or "state" interpretation of meaning--as opposed to the "stream" interpretation of meaning. The second usage is most important in the PI and $z$. In these later works, Wittgenstein uses "picture" sometimes in one way, sometimes in another. This is why I have used the less Tractatuscolored term of "field" to refer to the static aspect of meaning expressed in the later works. (In clarifying this distinction, I owe thanks to Dr. John Carlson.)

${ }^{3}$ on the fact that we should always allow the image before our mind some fluidity, wittgenstein writes: "Always get rid of the idea of the private object in this way: assume that it constantly changes, but that you do not notice the change because your memory constantly decieves you" (PI. p. 207).

Also cf. Z 33: "It often strikes us as if in grasping meaning the mind made small rudimentary movements, like someone irresolute who does not know which way to go--i.e.. it tentatively reviews the field [Gebiet] of possible applications [Anwendungen].

And $z$ 138: "It looks as if a sentence with, e.g., the word 'ball' in it already contained the shadow of other uses [Verwendungen] of this word. That is to say, the possibility of forming those other sentences." 
${ }^{4}$ For example, see $\underline{z} 233$; PI 71, 97, 607,609, p. 181, p. 212 .

5 The shift from Wittgenstein's concentration on the importance of "logical space" (in the Tractatus) to the importance of "the space of intentions" (in the PI and $z$ ) is the shift away from the primacy of possibility to the primacy of actuality. Cf. infra, pp. 12-13.

${ }^{6}$ See 2 41: "If I say 'I was then going to do such-and-such,' and if this statement is based on the thoughts, images, etc. which I remember, then someone else to whom I tell only these thoughts, images, etc. ought to be able to infer with as great a certainty as mine that I was then going to do such-and-such.--But often he could not do so. Indeed, were I myself to infer my intention from the evidence, other people would be right to say that this conclusion was very uncertain."

${ }^{7}$ See 2 373: "Concepts other than, though akin to, ours might sound very queer to us; deviations from the usual in an unusual direction."

2 381: "For the indefiniteness of our concept may be projected for us into the object that the word designates. So that if the indefiniteness were missing we should also not have 'the same thing meant.' The picture that we employ symbolizes the indefiniteness."

ours." 279: "And others have concepts that cut across

z 387: "For I want to say: an education quite different from ours might also be the foundation for quite different concepts."

2 388: "For here life would run on differently. - What interests us would not interest them. Here different concepts would no longer be unimaginable. In fact, this is the only way in which essentially different concepts are imaginable."

${ }^{8}$ This should be kept in mind particularly in the following section of this article.

${ }^{9}$ Also cf. 2 178: "The pecullar experience of meaning is characterized by the fact that we come out with an explanation and use the past tense." (Note how this whole discussion of trying to determine the meaningfulness of language in the stream is the linguistic application of Heisenberg's uncertainty principle.) 
${ }^{10}$ It should be noted parenthetically that this discussion of content and intention echoes in crucial in interpreting Wittgenstein's private language argument. CF. Infra, note 11 .

11 The similarity of the terms "familiar" and "familial" is not simply coincidental. For Wittgenstein, family resemblances have meaning insofar as they are considered as relationships of familarity in streams of personal experience. Insofar as such streams overlap in coinciding "forms of life," the meanings of our words are psychologically grounded in such a way as to negate the possibility of meaningful private languages. The key to Wittgenstein's family resemblances argument might be found in understanding objects as related to one another intentionally--that is, in terms of how they are, in fact, related as familiar in a stream or streams of experience. This familiartiy in the stream becomes the basis for ontological claims and for Wittgenstein's Investigations and zettel descriptions of the logical and pictorial (static or field) theories of meaning. The converse--that logical or pictorial theories of meaning act as the basis for meaning in the stream of experience--apparently is much less true of the later Wittgenstein than of the Wittgenstein of the Tractatus.

Frank Ebersole is feeling his way toward this interpretation of wittgenstein when he notes that "Wittgenstein writes as though 'being related to one another' and 'having relationships' were pretty much the same thing." CF. Frank B. Ebersole, "Reconsidering Some Passages in Wittgenstein," Canadian Journal of Philosophy, 2 (1972), p. 24.

12 cf. z 293: "I give the rules of a game. The other party makes a move, perfectly in accord with the rules, whose possibility I had not forseen, and which spoils the game, that is, as I had wanted it to be. I now have to say: 'I gave bad rules; I must change or perhaps add to my rules.' So in this way have $I$ a picture of the game in advance? In a sense: Yes."

\section{PI 125: "The fundamental fact here is that we} lay down rules, a technique, for a game, and that then when we follow the rules, things do not turn out as we had assumed. That we are therefore as it were entangled in our own rules. This entanglement in our rules is what we want to understand (i.e.., get a clear view of). It throws light on our concept of meaning something. For in those cases things turn out otherwise than we had meant, forseen. That is just what we say when, for example, a contradiction appears: 'I didn't mean it like that." " 
${ }^{13} \mathrm{Cf}$. also PI, p. 212: "Do I really see something different each time, or do I only interpret what $I$ see in a different way? I am inclined to say the former. But why?-To interpret is to think, to do something; seeing is a state." 